\title{
Septum resection in women with a septate uterus: a cohort study
}

\author{
J.F.W. Rikken I,*, K.W.J. Verhorstert' ${ }^{1}$, M.H. Emanuel' ${ }^{2}$, M.Y. Bongers ${ }^{3}$, \\ T. Spinder ${ }^{4}$, W. Kuchenbecker ${ }^{5}$, F.W. Jansen 6 , J.W. van der Steeg ${ }^{7}$, \\ C.A.H. Janssen ${ }^{8}$, K. Kapiteijn', W.A. Schols ${ }^{10}$, B. Torrenga ${ }^{11}$, \\ H.L. Torrance ${ }^{2}$, H.R. Verhoeve ${ }^{12}$, J.A.F. Huirne', A. Hoek ${ }^{13}$, \\ T.E. Nieboer ${ }^{14}$, I.A.J. van Rooij ${ }^{15}$, T.J. Clark ${ }^{16}$, L. Robinson ${ }^{16}$, \\ M.D. Stephenson ${ }^{17}$, B.W.J. Mol ${ }^{18}$, F. van der Veen', M. van Wely', and \\ M. Goddijn ${ }^{1, *}$
}

\begin{abstract}
'Centre for Reproductive Medicine and Department of Obstetrics and Gynaecology, Amsterdam University Medical Centre, Location AMC and VUMC, PO Box 22700, I 100 DE, Amsterdam, the Netherlands ${ }^{2}$ Department of Reproductive Medicine, University Medical Centre Utrecht, Utrecht, the Netherlands ${ }^{3}$ Department of Obstetrics and Gynaecology, Maxima Medical Centre, Eindhoven, the Netherlands ${ }^{4}$ Department of Obstetrics and Gynaecology, Leeuwarden Medical Centre, Leeuwarden, the Netherlands ${ }^{5}$ Department of Obstetrics and Gynaecology, Isala Hospital Zwolle, Zwolle, the Netherlands ${ }^{6}$ Department of Obstetrics and Gynaecology, University Medical Centre Leiden, Leiden, the Netherlands ${ }^{7}$ Department of Obstetrics and Gynaecology, Jeroen Bosch Hospital, Den Bosch, the Netherlands ${ }^{8}$ Department of Obstetrics and Gynaecology, Groene Hart Hospital, Gouda, the Netherlands ${ }^{9}$ Department of Obstetrics and Gynaecology, Reinier de Graaf Gasthuis, Delft, the Netherlands ${ }^{10}$ Department of Obstetrics and Gynaecology, Meander Medical Centre, Amersfoort, the Netherlands "Department of Obstetrics and Gynaecology, lkazia Hospital, Rotterdam, the Netherlands ${ }^{12}$ Department of Obstetrics and Gynaecology, OLVG Oost, Amsterdam, the Netherlands ${ }^{13}$ Department of Obstetrics and Gynaecology, University of Groningen, University Medical Center Groningen, Groningen, the Netherlands ${ }^{14}$ Department of Obstetrics and Gynaecology, Nijmegen, the Netherlands ${ }^{15}$ Department of Obstetrics and Gynaecology, Elisabeth Hospital Tweesteden, Tilburg, the Netherlands ${ }^{16}$ Department of Obstetrics and Gynaecology, Birmingham Women's and Children's Hospital, Birmingham, UK ${ }^{17}$ Department of Obstetrics and Gynaecology, University of Illinois, CA, USA ${ }^{18}$ Department of Obstetrics and Gynaecology, Monash University, Monash Medical Centre, Clayton, Victoria, Australia
\end{abstract}

*Correspondence address. Tel: 31-20-566 3857; Fax: 31-20-696 3489; E-mail: j.f.rikken@amsterdamumc.nl, m.goddijn@amsterdamumc.nl Submitted on July 12, 2019; resubmitted on November 20, 2019; editorial decision on December 5, 2019

STUDY QUESTION: Does septum resection improve reproductive outcomes in women with a septate uterus? SUMMARY ANSWER: In women with a septate uterus, septum resection does not increase live birth rate nor does it decrease the rates of pregnancy loss or preterm birth, compared with expectant management.

WHAT IS KNOWN ALREADY: The septate uterus is the most common uterine anomaly with an estimated prevalence of $0.2-2.3 \%$ in women of reproductive age, depending on the classification system. The definition of the septate uterus has been a long-lasting and ongoing subject of debate, and currently two classification systems are used worldwide. Women with a septate uterus may be at increased risk of subfertility, pregnancy loss, preterm birth and foetal malpresentation. Based on low quality evidence, current guidelines recommend removal of the intrauterine septum or, more cautiously, state that the procedure should be evaluated in future studies.

STUDY DESIGN, SIZE, DURATION: We performed an international multicentre cohort study in which we identified women mainly retrospectively by searching in electronic patient files, medical records and databases within the time frame of January 2000 until August 2018. Searching of the databases, files and records took place between January 2016 and July 2018 . By doing so, we collected data on 257 women with a septate uterus in 21 centres in the Netherlands, USA and UK.

PARTICIPANTS/MATERIALS, SETTING, METHODS: We included women with a septate uterus, defined by the treating physician, according to the classification system at that time. The women were ascertained among those with a history of subfertility, pregnancy loss, preterm birth or foetal malpresentation or during a routine diagnostic procedure. Allocation to septum resection or expectant management was dependent on the reproductive history and severity of the disease. We excluded women who did not have a wish to conceive at time of diagnosis. The primary outcome was live birth. Secondary outcomes included pregnancy loss, preterm birth and foetal malpresentation. All conceptions during follow-up were registered but for the comparative analyses, only the first live birth or ongoing pregnancy was included. To evaluate differences in live birth and ongoing pregnancy, we used Cox proportional regression to calculate hazard rates (HRs) and $95 \% \mathrm{Cl}$. To evaluate differences in pregnancy loss, preterm birth and foetal malpresentation, we used logistic regression to calculate odds ratios (OR) with corresponding $95 \% \mathrm{Cl}$. We adjusted all reproductive outcomes for possible confounders.

(C) The Author(s) 2020. Published by Oxford University Press on behalf of the European Society of Human Reproduction and Embryology.

This is an Open Access article distributed under the terms of the Creative Commons Attribution Non-Commercial License (http://creativecommons.org/licenses/by-nc/4.0/), which permits non-commercial re-use, distribution, and reproduction in any medium, provided the original work is properly cited. For commercial re-use, please contact journals.permissions@oup.com 
MAIN RESULTS AND THE ROLE OF CHANCE: In total, 257 women were included in the cohort. Of these, I5I women underwent a septum resection and 106 women had expectant management. The median follow-up time was 46 months. During this time, live birth occurred in 80 women following a septum resection (53.0\%) compared to 76 women following expectant management (7I.7\%) (HR 0.7I $95 \% \mathrm{Cl}$ 0.49-1.02) and ongoing pregnancy occurred in 89 women who underwent septum resection (58.9\%), compared to 80 women who had expectant management (75.5\%) (HR 0.74 (95\% Cl 0.52-1.06)). Pregnancy loss occurred in 5 I women who underwent septum resection (46.8\%) versus 31 women who had expectant management (34.4\%) (OR I.58 (0.8I-3.09)), while preterm birth occurred in 26 women who underwent septum resection (29.2\%) versus 13 women who had expectant management (I6.7\%) (OR I.26 (95\% Cl 0.52-3.04)) and foetal malpresentation occurred in 17 women who underwent septum resection (19.1\%) versus 27 women who had expectant management (34.6\%) (OR 0.56 (95\% Cl 0.24-I.33)).

LIMITATIONS, REASONS FOR CAUTION: Our retrospective study has a less robust design compared with a randomized controlled trial. Over the years, the ideas about the definition of the septate uterus has changed, but since the 257 women with a septate uterus included in this study had been diagnosed by their treating physician according to the leading classification system at that time, the data of this study reflect the daily practice of recent decades. Despite correcting for the most relevant patient characteristics, our estimates might not be free of residual confounding.

WIDER IMPLICATIONS OF THE FINDINGS: Our results suggest that septum resection, a procedure that is widely offered and associated with financial costs for society, healthcare systems or individuals, does not lead to improved reproductive outcomes compared to expectant management for women with a septate uterus. The results of this study need to be confirmed in randomized clinical trials.

STUDY FUNDING/COMPETING INTEREST(S): A travel for JFWR to Chicago was supported by the Jo Kolk Studyfund. Otherwise, no specific funding was received for this study. The Department of Obstetrics and Gynaecology, University Medical Centre, Groningen, received an unrestricted educational grant from Ferring Pharmaceutical Company unrelated to the present study. BWM reports grants from NHMRC, personal fees from ObsEva, personal fees from Merck, personal fees from Guerbet, other payment from Guerbet and grants from Merck, outside the submitted work. The other authors declare no conficts of interest.

\section{TRIAL REGISTRATION NUMBER: N/A}

Key words: septum resection / septate uterus / live birth / pregnancy loss / subfertility

\section{Introduction}

The septate uterus is the most common uterine anomaly with an estimated prevalence of $0.2-2.3 \%$ in women of reproductive age, depending on the diagnostic method and classification system (Chan et al., 20 I I a; Ludwin and Ludwin, 20 I5). Women with a septate uterus may be at increased risk of subfertility, pregnancy loss, preterm delivery and foetal malpresentation (Chan et al., 20l lb). The classification of uterine anomalies, and the definition of the septate uterus in particular, is a long-lasting and ongoing subject of debate, and currently two main classification systems are used worldwide: the ASRM (AFS) classification of 1988 that was modified in 2016 and the ESHRE-ESGE classification of 2013 (Grimbizis et al., 20 I3; ASRM, 20 I6; Ludwin et al., 20 I8). Compared to the ASRM classification, the ESHRE-ESGE classification seems to lead to an over diagnosis of the septate uterus, using the uterine wall thickness as part of their definition (Ludwin and Ludwin, 2015). Since both classification systems have not found a worldwide acceptance so far, in 2018 a study assessed the level of agreement between experts in distinguishing between a septate and normal/arcuate and used this agreement as a reference standard called Congenital Uterine Malformation by Experts (CUME) (Ludwin et al., 20I8).

The biological basis for the impaired reproductive outcomes in women with a septate uterus has not yet been clarified. According to a recent systematic literature review, the vascularization, myometrium and endometrium of the intrauterine septum are similar to the normal uterine wall. The only pathophysiological differences seem to be a lower expression of HOXAIO genes and VEGF receptor genes and a lower number of glandular and ciliated cells in the endometrial lining of the intrauterine septum. The reviewers concluded that these differences in histological composition of the endometrium, or the presence of the septum itself or other yet unknown factors, possibly account for the impaired reproductive outcomes (Rikken et al., 2019).

To improve reproductive outcomes, hysteroscopic septum resection has long been the standard of care in women with a septate uterus (Valle and Ekpo, 2013). Current evidence for this procedure is based on observational studies in which all women underwent septum resection in before/after design studies and in non-randomized comparative studies in which women could choose between septum resection and expectant management. Based on this low quality evidence (Grade C) current guidelines have different recommendations: the ASRM guideline for septate uterus recommends to remove the intrauterine septum (ASRM, 2016); the NICE guideline of recurrent miscarriage states that 'current evidence on efficacy is adequate to support the use of this procedure provided that normal arrangements are in place for clinical governance, consent and audit'; and the ESHRE guideline for recurrent pregnancy loss and the RCOG guideline recurrent miscarriage recommend not to perform the surgery and state that the procedure should be evaluated in future studies (RCOG, 20 I I; NICE, 2015; ESHRE, 2017).

In view of the persisting uncertainty around the effectiveness of septum resection, we performed a large international multicentre cohort study in women with a septate uterus and a wish to conceive, who electively chose for septum resection or expectant management. In this study we corrected for all possible confounders. Our aim was to determine whether hysteroscopic septum resection improves reproductive outcomes in these women. 


\section{Materials and Methods}

\section{Design}

This study was an international multicentre cohort study including women with a septate uterus with a wish to conceive. We constructed the manuscript according to the STROBE guideline.

\section{Recruitment and follow-up}

We included women mainly retrospectively in 18 centres in the Netherlands, 2 centres in the USA and I centre in the UK. First, in all centres in the Netherlands, USA and UK, we identified women retrospectively by searching via keywords 'septate uterus', 'uterus anomaly' and 'septum resection' in electronic patient files and medical records, within the time frame of January 2000 until August 2018. At the University of Illinois, Chicago, we also identified women searching via the keywords 'septate uterus' and 'uterus anomaly' in a recurrent pregnancy loss database. The database search took place between January 2016 and May 2018 in the Netherlands, between April and June 2017 in the USA and between June and July 2018 in the UK. In addition, we included women prospectively in the Dutch centres. After having obtained ethical approval for this cohort study in March 2015, women who declined to participate in the TRUST study (a randomized controlled trial in which women with a septate uterus are allocated to septum resection or expectant management, NTR 1676) were asked to participate in the current study until August 2018. We extracted data on baseline characteristics, interventions and on all pregnancies that occurred during follow-up via their medical records. In the Netherlands, eligible women were, if necessary, contacted by their physician to complete follow-up.

\section{Study population}

The study population consisted of women with a septate uterus and a wish to conceive. Allocation to septum resection or expectant management was arbitrary and dependent on the reproductive history and severity of the disease. The septate uterus was ascertained in women with a history of subfertility, pregnancy loss or preterm birth but could also have been identified during a gynaecological examination, an ultrasound in pregnancy or during a caesarean section.

\section{Definitions}

Subfertility was defined as the inability to conceive for a minimal period of I year of trying to conceive (Zegers-Hochschild et al., 2017); a conception was defined as a positive pregnancy test; ongoing pregnancy was defined as a viable intrauterine pregnancy of at least 12 weeks duration confirmed on an ultrasound scan (Braakhekke et al., 20 I4); a pregnancy loss was defined as the spontaneous demise of a pregnancy before 24 weeks of gestation; recurrent pregnancy loss was defined as two or more, not necessarily consecutive, pregnancy losses before 24 weeks of gestational age (ESHRE, 2017); preterm birth was defined as birth before a gestational age of 37 complete weeks (Blencowe et al., 20l3); and foetal malpresentation was defined as a non-cephalic presentation of the foetus at term. A septate uterus was defined by the treating physician, according to the classification system at that time (AFS, 1988; Grimbizis et al., 2013; ASRM, 2016).

The presence of a septate uterus was ascertained by hysterosalpingography (HSG), 3D ultrasound (3D-US), MRI, saline or gel infusion sonohysterography or hysteroscopy combined with laparoscopy (Faivre et al., 2012; Ludwin et al., 2014a; Siam and Soliman, 20I4; Graupera et al., 20।5).

The moment of diagnosis of the septate uterus was time zero; all pregnancies before diagnosis were considered obstetrical history, and all pregnancies after diagnosis were follow-up. When the septate uterus was found in pregnancy, we decided to take that pregnancy as obstetrical history and all subsequent pregnancies as follow-up.

\section{Ethical approval}

The Medical Ethical Committee of the Academic Medical Centre, Amsterdam, the Netherlands, stated that the Medical Research Involving Human Subjects Act (WMO) did not apply to this study and that an official approval of this study by our committee was not required (WI7_05I). In the Netherlands, all women gave informed consent for this study. In the USA, we used a recurrent pregnancy loss database created by one of the co-authors (MDS) for which women consented previously and previous ethical approval was obtained from the Institutional Review Board at the University of Chicago and the University of Illinois at Chicago, USA (\#2017-0324). In the UK, we obtained ethical approval for use of a research database of women with a septate uterus (IRAS project ID 268876) without requiring informed consent.

\section{Outcome measures}

The primary outcome measure was live birth, defined as the birth of a living child beyond 24 weeks of gestational age. Secondary outcomes were ongoing pregnancy, early pregnancy loss, preterm birth and foetal malpresentation.

\section{Statistical analyses}

A descriptive analysis was performed to compare baseline characteristics between women in the septum resection and expectant management arms. All conceptions during follow-up were registered but for the comparative analyses, only the first live birth or ongoing pregnancy was used.

To evaluate differences in live birth and ongoing pregnancy between the women in the two arms while accounting for follow-up time, we used Cox proportional regression to calculate hazard rates (HRs) and $95 \% \mathrm{Cl}$. To evaluate differences in pregnancy loss, preterm birth and foetal malpresentation, we used logistic regression to calculate odds ratios (OR) with corresponding $95 \% \mathrm{Cl}$. We adjusted for age, BMI, smoking, ethnicity, country, classification, diagnostic procedure, subfertility, pregnancy loss, preterm birth and previous live birth. To visualize differences in predicted proportion of live birth over time between women who underwent septum resection and women who had expectant management, we plotted adjusted survival curves. Women in whom the septate uterus was diagnosed during their pregnancy were included in all analyses, except when we evaluated differences in live birth within I year after diagnosis of the septate 


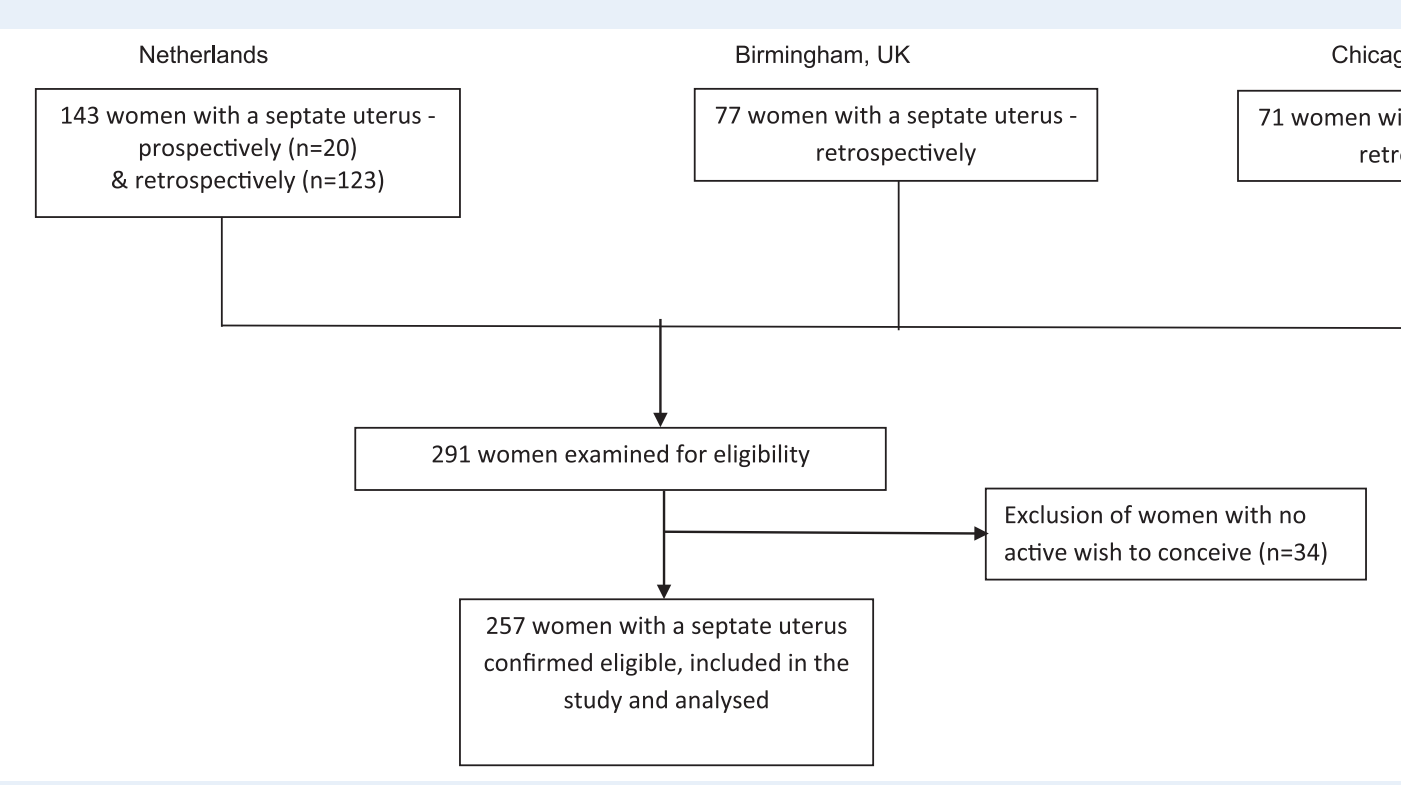

Figure I Flowchart of recruitment and inclusion/exclusion criteria.

uterus, as the pregnancy at time zero affects the time to a subsequent analysis. To explore differences in women with a history of pregnancy loss or a history of subfertility separately, we performed subanalyses in these women. We imputed any missing values for potential confounders for which we adjusted in the analyses using the MICE method for multiple imputation with standard errors based on Rubin's (2004) rule. All statistical analyses were performed using SPSS Statistics 25 .

\section{Results}

\section{Participants}

After obtaining approval in 2015 , we included 20 women prospectively in the Netherlands. In retrospect, we identified 123 women in the Netherlands, 77 in the UK and 7I in the USA. Of the 29I women we examined for eligibility, we excluded 34 women because they did not have a wish to conceive at time of diagnosis. In total, 257 women were confirmed eligible and were included in the study for analysis (Fig. I).

\section{Baseline characteristics}

Women had a septum diagnosed between February $198 \mathrm{I}$ and March 2018. Of the 257 included women, I5I women underwent septum resection and 106 women had expectant management. Baseline characteristics are summarized in Table I. In women who underwent septum resection, a lower percentage was of Caucasian origin compared to women who had expectant management. Between countries, there was a difference in distribution of women who underwent septum resection and who had expectant management. In women who underwent septum resection, ascertainment of the septate uterus was significantly different compared to women who had expectant management $(P<0.00 \mathrm{I})$. More women who underwent septum resection had a history of subfertility ( $n=54$ vs $n=21$ ). In women in whom the septate uterus was ascertained in pregnancy, fewer women underwent septum resection compared to women who had expectant management $(n=0$ vs $n=19)$. In 10 of the 19 women who had expectant management and in whom the septate uterus was ascertained in pregnancy, the septate uterus was diagnosed during caesarean section because of malpresentation. Women who underwent septum resection had a significantly lower percentage of previous live birth compared with women who had expectant management ( $n=25$ (16.6\%) vs $n=39$ (36.8\%), $P<0.00$ I). The majority of included women were diagnosed with a partial septate uterus: 119 women who underwent septum resection ( $81.5 \%)$ and 87 women who had expectant management (86.1\%). The septate uterus was mainly diagnosed by hysteroscopy combined with laparoscopy, as was the case in 76 women who underwent septum resection (52.8\%) and 33 women who had expectant management (31.7\%).

\section{Septum resection}

In I5I women who underwent septum resection, 73 women (48.3\%) had the procedure performed with a Versa point device, 32 women (21.2\%) with scissors, 12 women (7.9\%) with electro-surgery and in 34 women the technique of septum resection was unknown. Control of the depth of the resection was performed via laparoscopy $(n=59$ women) or via ultrasound ( $n=4$ women) or such control was not performed $(n=60)$. The intrauterine septum was completely removed in 128 (84.8\%) of included women. Complications occurred in seven women (4.6\%); in three women there was a perforation, in one woman the maximal allowed amount of intravasation was reached and in three women there was more blood loss than was deemed acceptable. In all of these seven women, the procedure was stopped prematurely and a second procedure was done without any complications. Control hysteroscopy was performed in 72 women (47.7\%), and in 16 of these women (10.6\%) a second septum resection was performed. 
Table I Baseline characteristics.

\begin{tabular}{|c|c|c|c|c|c|}
\hline & Septum resection $(n=|5|)$ & & Expectant management $(n=106)$ & & $P$-value \\
\hline Age (mean, SD) & $31.7(4.18)$ & & $30.8(5.09)$ & & 0.10 \\
\hline BMI (mean, SD) & $25.4(5.11)$ & & $24.8(5.02)$ & & 0.34 \\
\hline Ethnicity & & & & & 0.001 \\
\hline Caucasian & 119 & $(83.8 \%)$ & 88 & $(89.8 \%)$ & \\
\hline Non-Caucasian & 23 & $(16.1 \%)$ & 10 & $(10.3 \%)$ & \\
\hline Unknown & 9 & & 8 & & \\
\hline Country & & & & & $<0.001$ \\
\hline The Netherlands & 65 & $(43.0 \%)$ & 66 & $(62.3 \%)$ & \\
\hline Birmingham, UK & 48 & $(31.8 \%)$ & 7 & $(6.6 \%)$ & \\
\hline Chicago, USA & 38 & $(25.2 \%)$ & 33 & $(31.1 \%)$ & \\
\hline Smoking & & & & & 0.45 \\
\hline Yes & 12 & $(8 \%)$ & 5 & $(4.8 \%)$ & \\
\hline No & 138 & $(92 \%)$ & 99 & $(95.2 \%)$ & \\
\hline Unknown & I & & 2 & & \\
\hline Ascertainment & & & & & $<0.001$ \\
\hline Subfertility & 54 & $(36.0 \%)$ & 21 & $(20.4 \%)$ & \\
\hline Pregnancy loss & 72 & $(48.0 \%)$ & 43 & $(41.8 \%)$ & \\
\hline Preterm birth & 19 & $(12.7 \%)$ & 11 & $(10.7 \%)$ & \\
\hline In pregnancy & 0 & $(0 \%)$ & 19 & $(18.4 \%)$ & \\
\hline Other & 5 & $(3.3 \%)$ & 9 & $(8.7 \%)$ & \\
\hline Unknown & 1 & & 3 & & \\
\hline Previous live birth & & & & & $<0.001$ \\
\hline Yes & 25 & $(16.6 \%)$ & 39 & $(36.8 \%)$ & \\
\hline No & 126 & $(83.4 \%)$ & 67 & $(63.2 \%)$ & \\
\hline Classification & & & & & 0.39 \\
\hline Partial septate uterus & 119 & $(81.5 \%)$ & 87 & $(86.1 \%)$ & \\
\hline Complete septate uterus & 27 & $(18.5 \%)$ & 14 & $(13.9 \%)$ & \\
\hline Unknown & 5 & & 5 & & \\
\hline Diagnostic procedure & & & & & $<0.001$ \\
\hline $\mathrm{SIS} / \mathrm{GIS}$ & 8 & $(5.6 \%)$ & 9 & $(8.7 \%)$ & \\
\hline 3D US & 9 & $(6.3 \%)$ & 20 & $(19.2 \%)$ & \\
\hline MRI & 22 & $(15.3 \%)$ & 8 & $(7.7 \%)$ & \\
\hline Hyst+lap & 76 & $(52.8 \%)$ & 33 & $(31.7 \%)$ & \\
\hline HSG & 29 & $(20.1 \%)$ & 21 & $(20.2 \%)$ & \\
\hline Caesarean Section & 0 & $(0 \%)$ & 13 & $(12.5 \%)$ & \\
\hline Unknown & 7 & & 2 & & \\
\hline
\end{tabular}




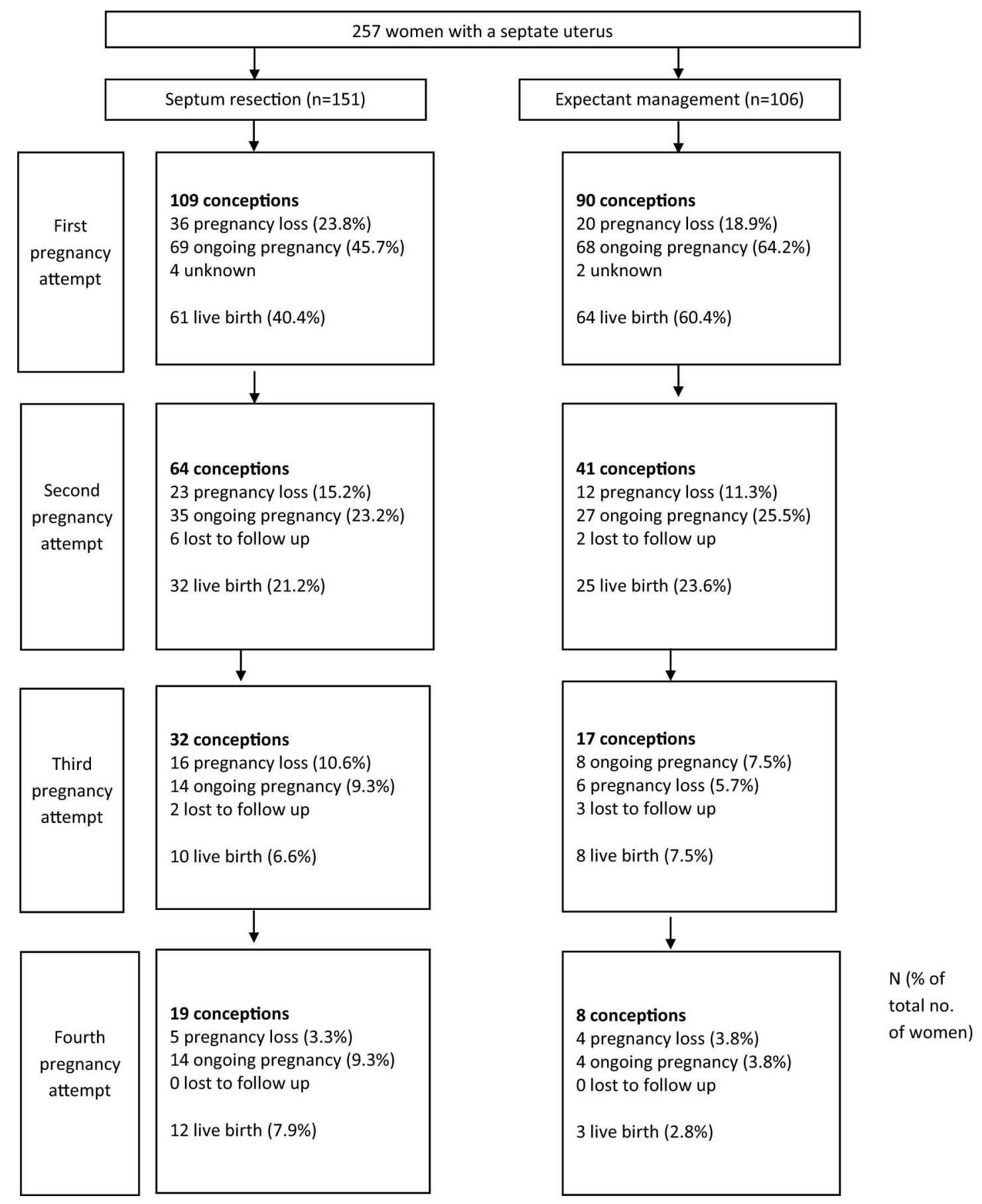

Figure 2 Flow diagram of reproductive outcomes.

\section{Long-term reproductive outcomes}

The flow of women during the follow-up of the study is shown in Fig. 2. The median duration of follow-up was 46 months: 40 months for women who underwent septum resection and 53 months for women who had expectant management.

The reproductive outcomes are shown in Table II. Overall, 80 of I5I women who underwent septum resection (53.0\%) had at least one live birth, compared to 76 of 106 women who had expectant
Expectant management $(n=106)$

$\mathrm{N}(\%$ of total no. of women) management (7I.7\%) (HR 0.7I (95\% Cl 0.49-I.02)) (Table II). There were no significant differences in cumulative live birth between women who underwent septum resection and women who had expectant management, as can be seen in the survival plot adjusted for confounders (Fig. 3). When we analysed the chance of a live birth within I year after diagnosis of the septate uterus, 32 women who underwent septum resection had a live birth (21.2\%) compared to 36 women who had expectant management (37.1\%) (HR 0.45 (95\% Cl 0.27-0.75)). 


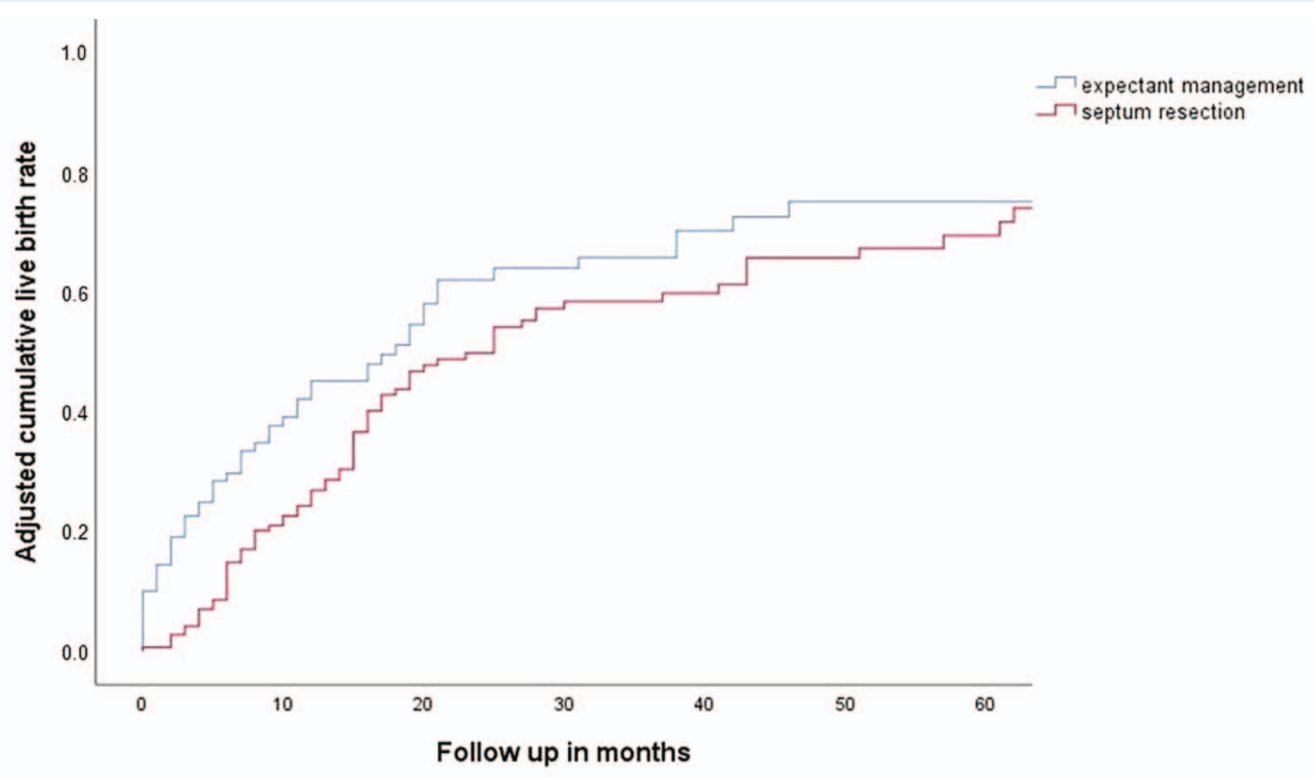

Figure 3 Adjusted cumulative live birth. Adjusted for age, BMI, smoking, ethnicity, country, classification, diagnostic procedure, subfertility, pregnancy loss, preterm birth and previous live birth.

Women who underwent septum resection had a non-significantly decreased chance of ongoing pregnancy (HR 0.74 (95\% Cl 0.52-I.06)) and foetal malpresentation (OR 0.56 (95\% Cl 0.24-I.33)), and a nonsignificantly increased chance of pregnancy loss (OR $1.58(95 \% \mathrm{Cl}$ $0.8 \mathrm{I}-3.09)$ and preterm birth (OR I.26 (95\% Cl 0.52-3.04)) (Table II). All malpresentations were breech.

\section{Subgroup analyses}

Women with an obstetrical history of one or more pregnancy losses and who underwent septum resection had an increased risk of another pregnancy loss, compared to women who had expectant management (OR 2.65 (95\% Cl I.05-6.67)) (Table III). In women with a history of subfertility, there were no differences in reproductive outcomes between the two groups (Table IV). In a subanalysis on women with a complete septate uterus, women who underwent septum resection had a decreased chance on an ongoing pregnancy, compared to women who had expectant management (HR 0.26 (0.07-0.9I)) (Supplementary Table SI).

\section{Discussion}

In this cohort study, more than half of the women with a septate uterus had a live birth. Septum resection did not lead to improved reproductive outcomes compared to expectant management in these women; septum resection did not increase the chance of live birth, nor did it decrease the chance of pregnancy loss or preterm birth. In contrast, septum resection may have decreased the chance of foetal malpresentation.

\section{Strengths and limitations}

Our study has a number of strengths. First, for this multicentre cohort of women with a septate uterus, we collected data in various centres worldwide, with a specifically large proportion of women who had expectant management. The relatively large sample size in combination with a long follow-up resulted in a unique study population, which embodies daily practice as well as possible. Second, since a retrospective study is by design at risk of selection bias, we adjusted for possible differences in prognostic factors between women who underwent a septum resection and women who had expectant management. Third, the observational study design enabled us to thoroughly describe baseline characteristics as well as reproductive outcomes.

Our study has also limitations. First, an adequately powered, randomized controlled trial obviously offers the best way to evaluate the effectiveness of septum resection compared to expectant management. Our observational study following a cohort of women with a septate uterus who either underwent septum resection or had expectant management is a less robust design. In this cohort particularly, women who chose expectant management could be considered as 'better prognosis patients', since 19 women who chose expectant management were pregnant at time of diagnosis of the septate uterus, compared to none of the women who underwent septum resection. We tried to correct all analyses for the most important patient characteristics, but nevertheless our results could still be influenced by residual confounding.

Second, we collected the data of women with a septate uterus between 1981 and 2018, and during that period the ideas and concepts on the classification of uterine anomalies and the best diagnostic tool to differentiate between septate, arcuate and bicornuate uterus changed (Ludwin and Ludwin, 20I5). In fact, the discussion about the most accurate definition of the septate uterus is still ongoing (Grimbizis et al., 2013; ASRM, 2016; Ludwin et al., 2018; Ludwin et al., 2019). In addition, saline or gel infusion sonohysterography and $3 \mathrm{D}$-ultrasound is currently considered as the most accurate test for diagnosing the septate uterus, but this was not available in the 
Table II Reproductive outcomes.

\begin{tabular}{|c|c|c|c|}
\hline & $\begin{array}{l}\text { Septum } \\
\text { resection } \\
(n=15 I)\end{array}$ & $\begin{array}{c}\text { Expectant } \\
\text { management } \\
(n=106)\end{array}$ & $\begin{array}{c}\text { OR/HR } \\
(95 \% \mathrm{CI})\end{array}$ \\
\hline \multicolumn{3}{|l|}{ Conception } & $\begin{array}{c}\text { HR } 0.74 \\
(0.53-1.02)\end{array}$ \\
\hline Yes & $109(72.2 \%)$ & $90(84.9 \%)$ & \\
\hline No & $42(27.8 \%)$ & $16(15.1 \%)$ & \\
\hline \multicolumn{3}{|l|}{ Live birth } & $\begin{array}{c}\text { HR 0.7I } \\
(0.49-1.02)\end{array}$ \\
\hline Yes & $80(53.0 \%)$ & $76(71.7 \%)$ & \\
\hline No & $71(47.0 \%)$ & $30(28.3 \%)$ & \\
\hline \multicolumn{3}{|l|}{$\begin{array}{l}\text { Ongoing } \\
\text { pregnancy }\end{array}$} & $\begin{array}{c}\text { HR } 0.74 \\
(0.52-1.06)\end{array}$ \\
\hline Yes & 89 (58.9\%) & $80(75.5 \%)$ & \\
\hline No & $62(41.1 \%)$ & $26(24.5 \%)$ & \\
\hline \multicolumn{3}{|c|}{ Pregnancy loss (\% of conception) } & $\begin{array}{c}\text { OR I.58 } \\
(0.8 \mathrm{I}-3.09)\end{array}$ \\
\hline Yes & $5 \mathrm{I}(46.8 \%)$ & $31(34.4 \%)$ & \\
\hline No & $58(53.2 \%)$ & $59(65.6 \%)$ & \\
\hline \multicolumn{3}{|c|}{ Preterm birth (\% of ongoing pregnancy) } & $\begin{array}{c}\text { OR I.26 } \\
(0.52-3.04)\end{array}$ \\
\hline Yes & $26(29.2 \%)$ & $13(16.7 \%)$ & \\
\hline No & $63(70.8 \%)$ & $65(83.3 \%)$ & \\
\hline Unknown & & 2 & \\
\hline \multicolumn{3}{|c|}{ Malpresentation (\% of ongoing pregnancy) } & $\begin{array}{c}\text { OR } 0.56 \\
(0.24-1.33)\end{array}$ \\
\hline Yes & $17(19.1 \%)$ & $27(34.6 \%)$ & \\
\hline No & $72(80.9 \%)$ & $51(65.4 \%)$ & \\
\hline Unknown & & 2 & \\
\hline
\end{tabular}

$\mathrm{OR}=$ odds rate, $\mathrm{HR}=$ hazard rate, $\mathrm{Cl}=$ confidence interval

Only the first live birth or first ongoing pregnancy per woman was included. All malpresentations were breech.

All outcomes were adjusted for age, BMI, smoking, ethnicity, country, classification, diagnostic procedure, subfertility, pregnancy loss, preterm birth and previous live birth.

time period in which some of our patients were diagnosed (Ludwin et al., 20I4a). In this pragmatic study, we included 257 women with a septate uterus who were diagnosed by their treating physician in 21 centres worldwide, according to the leading classification system at that time. For all of these women, there was a decision to be made: to resect the septum or not. So, we here present the data of a retrospective cohort study that reflects the daily practice of the past four decades.

Third, the retrospective design inevitably implies that we have limited data on quality of surgical care and assessment of the anatomic results (Ludwin et al., 20l4b). Although we corrected our reproductive outcomes for the differentiation between a partial and complete septate uterus, we could not correct for size of the septum, since we had detailed information on the thickness of the septum in just 17 women (6.6\%) and information on the length of the septum in just 27 women (10.5\%). The size of the septum could have influenced the choice of
Table III Reproductive outcomes of all women with a history of pregnancy loss.

\begin{tabular}{|c|c|c|c|}
\hline & $\begin{array}{l}\text { Septum } \\
\text { resection } \\
(n=92)\end{array}$ & $\begin{array}{c}\text { Expectant } \\
\text { management } \\
(n=50)\end{array}$ & $\begin{array}{c}\text { OR/HR } \\
(95 \% \mathrm{CI})\end{array}$ \\
\hline \multicolumn{3}{|l|}{ Conception } & $\begin{array}{c}\text { HR } 0.69 \\
(0.45-1.06)\end{array}$ \\
\hline Yes & $72(78.3 \%)$ & $40(80 \%)$ & \\
\hline No & $20(21.7 \%)$ & $10(20 \%)$ & \\
\hline \multicolumn{3}{|l|}{ Live birth } & $\begin{array}{c}\text { HR 0.61 } \\
(0.36-1.02)\end{array}$ \\
\hline Yes & 47 (5।.1\%) & $29(58 \%)$ & \\
\hline No & 45 (48.9\%) & $21(42 \%)$ & \\
\hline \multicolumn{3}{|l|}{$\begin{array}{l}\text { Ongoing } \\
\text { pregnancy }\end{array}$} & $\begin{array}{c}\text { HR } 0.65 \\
(0.40-1.07)\end{array}$ \\
\hline Yes & $54(58.7 \%)$ & $32(64 \%)$ & \\
\hline No & $38(41.3 \%)$ & $18(36 \%)$ & \\
\hline \multicolumn{3}{|c|}{ Pregnancy loss (\% of conception) } & $\begin{array}{c}\text { OR } 2.65 \\
(1.05-6.67)\end{array}$ \\
\hline Yes & $42(58.3 \%)$ & $16(40 \%)$ & \\
\hline No & $30(41.7 \%)$ & $24(60 \%)$ & \\
\hline \multicolumn{3}{|c|}{ Preterm birth (\% of ongoing pregnancy) } & $\begin{array}{c}\text { OR I. } 23 \\
(0.35-4.30)\end{array}$ \\
\hline Yes & $19(35.1 \%)$ & $7(23.3 \%)$ & \\
\hline No & 35 (64.8\%) & $23(76.7 \%)$ & \\
\hline Unknown & & 2 & \\
\hline \multicolumn{3}{|c|}{ Malpresentation (\% of ongoing pregnancy) } & $\begin{array}{c}\text { OR } 0.99 \\
(0.23-4.29)\end{array}$ \\
\hline Yes & $9(14.8 \%)$ & $6(20 \%)$ & \\
\hline No & $46(85.2 \%)$ & $24(80 \%)$ & \\
\hline Unknown & & 2 & \\
\hline
\end{tabular}

$\mathrm{OR}=$ odds rate, $\mathrm{Cl}=$ confidence interval

Only the first live birth or first ongoing pregnancy per woman was included. All outcomes were adjusted for age, BMI, smoking, ethnicity, country, classification, diagnostic procedure, subfertility, preterm birth and previous live birth.

treatment of the patient or physician and possibly led to confounding by indication.

\section{Literature}

Our findings are in contrast with the current literature on septum resection. Observational studies with a before/after design have reported spectacular outcomes after septum resection, as summarized in a review in which live birth rates and pregnancy loss rates of 16 studies (658 women) were pooled: the number of term deliveries before and after septum resection were 34 (3\%) versus 395 (80\%) and the number of pregnancy losses were 933 (88\%) versus 67 (I4\%) (Homer et al., 2000). The results of these studies should be interpreted 
Table IV Reproductive outcomes of all women with a history of subfertility.

\begin{tabular}{|c|c|c|c|}
\hline & $\begin{array}{l}\text { Septum } \\
\text { resection } \\
(n=60)\end{array}$ & $\begin{array}{c}\text { Expectant } \\
\text { management } \\
(n=28)\end{array}$ & $\begin{array}{c}\text { OR/HR } \\
(95 \% \mathrm{Cl})\end{array}$ \\
\hline \multicolumn{3}{|l|}{ Conception } & $\begin{array}{c}\text { HR I.04 } \\
(0.76-1.44)\end{array}$ \\
\hline Yes & $38(63.3 \%)$ & $20(71.4 \%)$ & \\
\hline No & $22(36.7 \%)$ & $8(28.6 \%)$ & \\
\hline \multicolumn{3}{|l|}{ Live birth } & $\begin{array}{c}\text { HR } 0.90 \\
(0.63-1.28)\end{array}$ \\
\hline Yes & $32(53.3 \%)$ & $17(60.7 \%)$ & \\
\hline No & $28(46.7 \%)$ & II (39.3\%) & \\
\hline \multicolumn{3}{|l|}{$\begin{array}{l}\text { Ongoing } \\
\text { pregnancy }\end{array}$} & $\begin{array}{c}\text { HR I.04 } \\
(0.74-1.48)\end{array}$ \\
\hline Yes & 35 (58.3\%) & 17 (60.7\%) & \\
\hline No & $25(41.7 \%)$ & II (39.3\%) & \\
\hline \multicolumn{3}{|c|}{ Pregnancy loss (\% of conception) } & $\begin{array}{c}\text { OR I.07 } \\
(0.28-4.13)\end{array}$ \\
\hline Yes & 15 (39.5\%) & $9(45 \%)$ & \\
\hline No & $23(60.5 \%)$ & II (55\%) & \\
\hline \multicolumn{3}{|c|}{ Preterm birth (\% of ongoing pregnancy) } & $\begin{array}{c}\text { OR I.75 } \\
(0.17-17.54)\end{array}$ \\
\hline Yes & $9(25.7 \%)$ & $4(23.5 \%)$ & \\
\hline No & $26(74.3 \%)$ & $13(76.5 \%)$ & \\
\hline \multicolumn{3}{|c|}{ Malpresentation (\% of ongoing pregnancy) } & $\begin{array}{c}\text { OR } 0.39 \\
(0.08-2.03)\end{array}$ \\
\hline Yes & $9(25.7 \%)$ & $8(47.1 \%)$ & \\
\hline No & $26(74.3 \%)$ & $9(52.9 \%)$ & \\
\hline
\end{tabular}

$\mathrm{OR}=$ odds rate, $\mathrm{Cl}=$ confidence interval

Only the first live birth or first ongoing pregnancy per woman was included. All outcomes were adjusted for age, BMI, smoking, ethnicity, country, classification, diagnostic procedure, pregnancy loss, preterm birth and previous live birth.

with caution for two reasons: first, the 'before/after' design always favours the tested intervention. Second, these studies did not correct for confounders. The results of non-randomized comparative studies in which all women underwent septum resection or had expectant management showed either positive effects of septum resection or no differences in reproductive outcome (Chan et al., 20 I lb). None of these studies corrected for confounding variables. Four studies had a very small sample size with, respectively, II women (Maneschi et al., 199I), 43 women (Valli et al., 2004), 35 women (Lin et al., 2009) and 60 women (Pang et al., 201 I). Two studies were at high risk of selection bias because of the unequal distribution of women: 102 women who underwent septum resection versus 25 women who had expectant management (Tonguc et al., 20I I) and 109 women who underwent septum resection versus 15 women who had expectant management (Sugiura-Ogasawara et al., 20I5). We feel our results to be a better representation of the true effect of septum resection.
In our study we found a relatively high overall live birth rate: $53.0 \%$ in women who underwent septum resection and $71.7 \%$ in women who chose expectant management, which can be clarified by our long follow-up period and is in line with the live birth reported in literature (Pang et al., 20II; Sugiura-Ogasawara et al., 20I5). This explanation is supported by the observation that the chance of live birth within I year was $21.2 \%$ in women who underwent septum resection versus $37.1 \%$ in women who chose expectant management.

In women who underwent septum resection, 26 women had a preterm birth (29.2\%), compared to I 3 women who chose expectant management (I6.7\%) (OR I.26 (95\% Cl 0.52-3.04)). In women with a complete septate uterus, women who underwent septum resection had a decreased chance on an ongoing pregnancy compared to women who had expectant management ( $\mathrm{HR} 0.26$ ( $\mathrm{Cl} 0.07-0.91)$ ). These are unexpected findings that need to be confirmed or refuted in larger studies.

For decades, the recommendation worldwide has been to perform septum resection based on low-graded evidence. The procedure is widely offered but is associated with financial costs for the society, healthcare systems or individuals. We feel that we here have shown that septum resection is not without risks, has no clear benefits and should not be performed unless the evidence that it improves reproductive outcomes in women is convincingly solid.

\section{Conclusion}

In our study, septum resection does not lead to improved pregnancy outcomes compared to expectant management in women with a septate uterus. These findings underline that a randomized controlled trial is urgently needed. The follow-up of such an RCT is complete by the end of 2019 (Netherlands Trial Register (NTR) 1676). Awaiting those results, septum resection should not be performed unless as part of a clinical trial.

\section{Supplementary data}

Supplementary data are available at Human Reproduction online.

\section{Acknowledgements}

The authors would like to thank all of the participating hospitals: Amsterdam University Medical Centre, location AMC and VUMC, Medical Centre Leeuwarden, Spaarne Hospital, Jeroen Bosch Hospital, Isala Hospital, Radboud University Medical Centre, Maxima Medical Centre, Groene Hart Hospital, Reiner de Graaf Hospital, University Medical Centre Utrecht, Meander Medical Centre, OLVG Hospital, Ikazia Hospital, Leiden University Medical Centre, University Medical Centre Groningen and Tweesteden Hospital (the Netherlands), University of Illinois at Chicago and University of Chicago (USA), Birmingham Women's and Children's Hospital (UK).

\section{Authors' roles}

JFWR, MG, FvV and MvW conceived the study. JFWR was responsible for the logistical aspects of the study. KWJV helped with the start of the 
study. MHE, MYB, TS, WK, FWJ, JWS, CAHJ, KK, WAS, BT, HLT, HRV, JAFH, AH, TEN and IAJR managed the study in the different hospitals in the Netherlands. TJC and LR were responsible for the study in the UK and MDS was responsible for the study in the USA. JFWR and MvW analysed the data. JFWR, MG, FvV and MvW drafted the manuscript, supported by BWM. All authors contributed to the critical revision of the paper and approved the final manuscript.

\section{Funding}

A travel for JFWR to Chicago was supported by the Jo Kolk Studyfund. Otherwise, no specific funding was received for this study.

\section{Conflict of interest}

The Department of Obstetrics and Gynaecology, University Medical Centre, Groningen, received an unrestricted educational grant from Ferring Pharmaceutical Company unrelated to the present study. BWM reports grants from NHMRC, personal fees from ObsEva, personal fees from Merck, personal fees from Guerbet, other payment from Guerbet and grants from Merck, outside the submitted work. The other authors declare no conficts of interest.

\section{References}

AFS. The American Fertility Society classifications of adnexal adhesions, distal tubal occlusion, tubal occlusion secondary to tubal ligation, tubal pregnancies, mullerian anomalies and intrauterine adhesions. Fertil Steril 1988;49:944-955.

ASRM. Uterine septum: a guideline. Fertil Steril 2016; 1 06:530-540.

Blencowe H, Cousens S, Chou D, Oestergaard M, Say L, Moller AB, Kinney M, Lawn J. Born too soon: the global epidemiology of 15 million preterm births. Reprod Health 2013; 10:S2.

Braakhekke M, Kamphuis El, Dancet EA, Mol F, van der Veen F, Mol BW. Ongoing pregnancy qualifies best as the primary outcome measure of choice in trials in reproductive medicine: an opinion paper. Fertil Steril 20 I4; I O I: I 203-1204.

Chan YY, Jayaprakasan K, Tan A, Thornton JG, Coomarasamy A, Raine-Fenning NJ. Reproductive outcomes in women with congenital uterine anomalies: a systematic review. Ultrasound Obstet Gynecol 20I Ia;38:37I-382.

Chan YY, Jayaprakasan K, Zamora J, Thornton JG, Raine-Fenning N, Coomarasamy A. The prevalence of congenital uterine anomalies in unselected and high-risk populations: a systematic review. Hum Reprod Update 20 I Ib; 1 7:76I-77I.

ESHRE. Guideline Recurrent Pregnancy Loss. 20 17: I-I53.

Faivre E, Fernandez H, Deffieux X, Gervaise A, Frydman R, Levaillant JM. Accuracy of three-dimensional ultrasonography in differential diagnosis of septate and bicornuate uterus compared with office hysteroscopy and pelvic magnetic resonance imaging. J Minim Invasive Gynecol 2012;19:101-106.

Graupera B, Pascual MA, Hereter L, Browne JL, Ubeda B, Rodriguez I, Pedrero C. Accuracy of three-dimensional ultrasound compared with magnetic resonance imaging in diagnosis of Mullerian duct anomalies using ESHRE-ESGE consensus on the classification of congenital anomalies of the female genital tract. Ultrasound Obstet Gynecol 2015;46:616-622.
Grimbizis GF, Gordts S, Di Spiezo Sardo A, Brucker S, De Angelis C, Gergolet M, Li TC, Tanos V, Brolmann H, Gianaroli $L$ et al. The ESHRE/ESGE consensus on the classification of female genital tract congenital anomalies. Hum Reprod 2013;28: 2032-2044.

Homer HA, Li TC, Cooke ID. The septate uterus: a review of management and reproductive outcome. Fertil Steril 2000;73: I-I4.

Lin K, Zhu X, Xu H, Liang Z, Zhang X. Reproductive outcome following resectoscope metroplasty in women having a complete uterine septum with double cervix and vagina. Int J Gynaecol Obstet 2009; 1 05:25-28.

Ludwin A, Ludwin I. Comparison of the ESHRE-ESGE and ASRM classifications of Mullerian duct anomalies in everyday practice. Hum Reprod 2015;30:569-580.

Ludwin A, Ludwin I, Coelho Neto MA, Nastri CO, Bhagavath B, Lindheim SR, Martins WP. Septate uterus by updated ESHRE/ESGE, ASRM and CUME definitions: association with infertility, previous miscarriage, and warnings for women and healthcare systems, and associated cost analysis. Ultrasound Obstet Gynecol 2019;54: 800-814.

Ludwin A, Ludwin I, Kudla M, Pitynski K, Banas T, Jach R, Knafel A. Diagnostic accuracy of three-dimensional sonohysterography compared with office hysteroscopy and its interrater/intrarater agreement in uterine cavity assessment after hysteroscopic metroplasty. Fertil Steril 20 I4a; 10 I: 1392-1399.

Ludwin A, Ludwin I, Pitynski K, Banas T, Jach R. Role of morphologic characteristics of the uterine septum in the prediction and prevention of abnormal healing outcomes after hysteroscopic metroplasty. Hum Reprod 2014b;29: |420-|43|.

Ludwin A, Martins WP, Nastri CO, Ludwin I, Coelho Neto MA, Leitao VM, Acien M, Alcazar JL, Benacerraf B, Condous G et al. Congenital Uterine Malformation by Experts (CUME): better criteria for distinguishing between normal/arcuate and septate uterus? Ultrasound Obstet Gynecol 2018;5 I: 101-109.

Maneschi F, Parlato M, Incandela S, Maneschi M. Reproductive performance in women with complete septate uteri. J Reprod Med 199|;36:741-744.

NICE. NICE: hysteroscopic metroplasty of a uterine septum for primary. Inf Dent 20I5; I-8.

Pang LH, Li MJ, Li M, Xu H, Wei ZL. Not every subseptate uterus requires surgical correction to reduce poor reproductive outcome. Int J Gynaecol Obstet 20 I I; I I 5:260-263.

RCOG. Guideline: the investigation and treatment of couples with recurrent first-trimester and second-trimester miscarriage. 20II;I-18.

Rikken J, Leeuwis-Fedorovich NE, Letteboer S, Emanuel MH, Limpens J, van der Veen F, Goddijn M, van Wely M. The pathophysiology of the septate uterus: a systematic review. BJOG 2019;126: I192-1199.

Rubin D. Multiple Imputation for Nonresponse in Surveys. New York: John Wiley and Sons, 2004.

Siam S, Soliman BS. Combined laparoscopy and hysteroscopy for the detection of female genital system anomalies results of 3,81 I infertile women. J Reprod Med 20 14;59:542-546.

Sugiura-Ogasawara M, Lin BL, Aoki K, Maruyama T, Nakatsuka M, Ozawa N, Sugi T, Takeshita T, Nishida M. Does surgery improve live 
birth rates in patients with recurrent miscarriage caused by uterine anomalies? J Obstet Gynaecol 2015;35: 155-158.

Tonguc EA, Var T, Batioglu S. Hysteroscopic metroplasty in patients with a uterine septum and otherwise unexplained infertility. Int $J$ : Gynaecol Obstet 201 I; I 13:128-130.

Valle RF, Ekpo GE. Hysteroscopic metroplasty for the septate uterus: review and meta-analysis. J Minim Invasive Gynecol 2013;20: $22-42$.
Valli E, Vaquero E, Lazzarin N, Caserta D, Marconi D, Zupi E. Hysteroscopic metroplasty improves gestational outcome in women with recurrent spontaneous abortion. J Am Assoc Gynecol Laparosc 2004; I I:240-244.

Zegers-Hochschild F, Adamson GD, Dyer S, Racowsky C, de J, Sokol R, Rienzi L, Sunde A, Schmidt L, Cooke ID et al. The international glossary on infertility and fertility care 2017. Hum Reprod 2017;32: |786-|80|. 